\title{
Teoria dos modos de saber e educação dialógica em cursos de formação de professores a distância: conduta dos tutores nas atividades de estudo
}

\section{Fórum}

Elena Maria Mallmann*

\begin{abstract}
Resumo
O objetivo deste artigo é compreender como as condutas dos tutores, em atividades a distância, potencializam diálogo-problematizador e produção colaborativa em torno dos conteúdos curriculares. Problematiza-se as condutas dos tutores nas atividades de estudo Fórum no ambiente virtual de um curso de formação de professores a distância da Universidade Aberta do Brasil na Universidade Federal de Santa Maria (UAB/UFSM). Segundo pressupostos teórico-metodológicos da pesquisa-ação, a abordagem de procedimentos contou com aplicação de questionários tipo survey, observação participante e exploração da documentação do curso. A análise foi categorizada pelas condutas conectada e separada fundamentadas na teoria dos modos de saber e educação dialógica. Os resultados indicam que condutas conectada e separada dos tutores nas atividades de estudo Fórum em ambientes virtuais promovem diálogo-problematizador e produção colaborativa desde que os mesmos desenvolvam fluência nos conteúdos, no modelo pedagógico e nas tecnologias em rede. As conclusões pontuam que os princípios da teoria dos modos de saber na interface com a educação dialógica são basilares para potencializar a problematização conceitual e a produção colaborativa em torno dos conteúdos curriculares na educação a distância.
\end{abstract}

Palavras-chave: Educação a Distância. Tutoria a Distância. Fórum de Educação a Distância. 


\section{Introdução}

$\mathrm{Na}$ Educação a Distância (EaD) mediada por tecnologias educacionais em rede, os encontros presenciais são eventuais. Por isso, o processo de interação não é unicamente centrado na oralidade. Os Ambientes Virtuais de Ensino-Aprendizagem (AVEA) são integrados na mediação pedagógica como espaços escolares para problematização (estudo) dos conteúdos e produção conceitual colaborativa. Por conseguinte, conhecer e utilizar as ferramentas disponibilizadas nesses AVEA são ações fundamentais na prática pedagógica.

Nesse contexto, gestores, professores, tutores e estudantes precisam compreender que a gestão, o planejamento e a implementação de cursos na modalidade a distância implicam condutas multidisciplinares e colaborativas. As diversas formas de interação que ocorrem em AVEA focalizam um processo ensino-aprendizagem que não está mais centrado apenas no professor, mas sim na construção do conhecimento de forma colaborativa, multidirecional, problematizadora, em que todos os interagentes participam do processo.

Por isso, partimos do princípio epistemológico em que práticas pedagógicas pautadas no diálogo-problematizador são fundamentais. Nas atividades de estudo (DAVIDOV, 1999) colaborativas é possível desenvolver conhecimentos por meio da: a) discussão de argumentos; b) compreensão da tese de outras pessoas com proposição de novas perguntas e formulação de sínteses; c) descoberta de novos saberes a partir da experiência compartilhada e aplicação dos conhecimentos científicos na vida cotidiana; d) reflexão crítica em conjunto com os colegas. Esse processo gera construção social do conhecimento, conforme explicita Kenski (2003). Para tanto, é importante que sejam realizadas pesquisas com foco na investigação das condutas que, de fato, potencializam a colaboração e a problematização nas atividades de estudo em ambientes virtuais.

Tendo em vista essa necessidade temática emergente em educação, este artigo é síntese de resultados de pesquisa-ação desenvolvida ao longo de curso de mestrado. O propósito foi analisar como as condutas separada e conectada dos tutores nas Atividades de Estudo Fórum (AEF) do ambiente virtual Moodle potencializam problematização e produção colaborativa em torno dos conteúdos curriculares. No quadro epistemológico delimitado, foram evidenciadas interfaces conceituais entre a Teoria dos Modos de Saber (TMS) (BELENKY et al., 1986; CLINCHY, 1996) e a Educação Dialógico-Problematizadora (EDP) freiriana (FREIRE, 1987). 
Iniciamos explicitando os pressupostos e percurso metodológico da pesquisa realizada. $\mathrm{Na}$ segunda parte, destacamos conceitos das TMS e EDP integrando a discussão com a análise dos resultados organizada em torno de quadros conceituais e gráficos com resultados de questionários survey. Na terceira parte, argumentamos sobre o papel das condutas conectada e separada na educação a distância mediada por tecnologias educacionais em rede explicitando o potencial de ferramentas de atividades como as Pesquisas de Avaliação no Moodle. Na quarta parte, apresentamos proposta concreta de avaliação em AEF utilizando escalas de avaliação. Nas considerações finais, destacamos a importância das condutas conectada e separada dos tutores para potencializar diálogo e práticas colaborativas em cursos a distância.

\section{Pressupostos e percurso metodológico}

Em termos de abordagem metodológica e procedimentos de pesquisa, apontamos que as análises e reflexões interpretativas são oriundas de resultados de pesquisa-ação realizada no Curso de Graduação em Letras - Português e Literaturas a Distância da Universidade Aberta do Brasil na Universidade Federal de Santa Maria (UAB/UFSM). Tais resultados foram validados pelos pares tanto na comissão examinadora da dissertação de mestrado quanto em outras publicações acadêmicas.

Os passos da pesquisa se organizaram em duas dimensões: uma que fez menção ao processo reconstrutivo-construtivo, isto é, que englobaram observação participante como tutora-pesquisadora nos quatro passos essenciais dos ciclos em espiral da pesquisa-ação (planejamento, ação, observação e reflexão), originando os registros de ensino-aprendizagem dentro do ambiente virtual durante dois anos. Nesse caso, nossa ênfase foi nas mensagens nas AEF. Uma segunda dimensão envolveu estudo dos documentos do curso como o projeto pedagógico, momentos de interação entre os participantes e aplicação de um questionário survey em escala Likert com o grupo de tutores do curso.

Entendemos que a pesquisa-ação busca, ao mesmo tempo, conhecer e intervir na realidade na qual se desenvolvem as ações. O ciclo espiral, conforme Lewin (1946), é essencial para essas pesquisas, pois envolve a retomada em processo das ações, análises, reflexões, em uma dinâmica sempre evolutiva. Isto é, o processo não é estático, mas está em constante formulação e reformulação.

Na pesquisa implementada, os ciclos foram organizados de acordo com as disciplinas do curso de graduação em que atuamos, envolvendo planejamento, atuação, observação e reflexão. Em todas as 
disciplinas, foi realizada pelo menos uma AEF, na maioria por decisão do professor e em uma por nossa influência no planejamento das disciplinas apoiando o professor. Os feedbacks selecionados que serviram de exemplos ao longo do texto (mensagens em AEF) são de tutores diferentes. Os tutores não foram diferenciados, porque nosso intuito foi centrar no texto das mensagens postadas por eles nas AEF.

A análise foi realizada a partir de duas categorias: conduta conectada e conduta separada. Ou seja, na análise por categorias, realizamos a triangulação dos dados coletados durante os ciclos da pesquisa, identificando aspectos empíricos relevantes para sustentar nossa argumentação interpretativocrítica. A separação das condutas por categorias foi uma opção metodológica. Jamais intencionamos separar conceitualmente as duas condutas, já que ambas são fundamentais para o desenvolvimento da prática dialógico-problematizadora.

Durante esse percurso, tivemos a oportunidade de trabalhar com vários tutores e professores, somando um grupo de doze pessoas. Ao longo das quatro disciplinas em que pesquisamos ativamente, os tutores sempre tiveram participação, tanto no planejamento quanto na implementação das atividades propostas pelos professores, o que contribuiu para o desenvolvimento da pesquisa-ação como uma forma de estudar estratégias para aprimorar a prática de tutoria.

Nesse sentido, a sistematização de dados ocorreu por meio de várias fontes de dados. As observações ocorreram em vários momentos: reuniões, encontros presenciais nos polos, monitoramento das disciplinas sendo sempre registradas em diários de pesquisa. A análise dos dados foi fundamentada pela TMS e EDP, com o intuito de identificar os viáveis-possíveis e as situações-limites das condutas conectada e separada dos tutores em AEF. Tecemos relações entre TMS e estudos de Paulo Freire acerca da EDP e as implicações que tais condutas ocasionam para o processo ensino-aprendizagem.

Em relação aos métodos de coleta de dados, no âmbito da pesquisa-ação durante dois anos (2011/2012), sistematizamos: a) questionários (pesquisa tipo survey aplicada por meio do Moodle) proposto por livre adesão a 17 tutores do curso no segundo semestre de 2012, dos quais sete responderam; b) a observação sistemática, que consiste em diário de campo, contendo o relato de situações vivenciadas ao longo da pesquisa, que são pertinentes para o momento de reflexão crítica sobre a prática; c) a observação participante, que se relaciona ao diálogo e interação entre os participantes ocorridos por meio das ferramentas do Moodle e dos encontros presenciais com os estudantes nos polos da UAB/UFSM; d) análise das mensagens nas AEF; e) análise de documentos, 
que consiste no exame do projeto pedagógico que fundamenta as ações desenvolvidas no curso de graduação pesquisado.

Para realizar a análise, foram desenvolvidos critérios (Quadro 1) com base nos estudos realizados em torno da TMS (condutas conectada e separada), estabelecendo relações com a EDP. Como estratégia de orientação e identificação das condutas dos tutores nas AEF, os critérios foram elaborados como questionamentos, possibilitando, assim, a procura de respostas para tais perguntas. Essa ideia de elaboração dos critérios de verificação e análise das condutas dos tutores nas AEF foi especialmente pautada na estrutura dos questionários da ferramenta de atividade chamada Pesquisa de Avaliação disponível no Moodle. São os formulários em escalas tipo Likert (Concordo Plenamente, Concordo em Parte, Não Concordo nem Discordo, Discordo em Parte, Discordo Plenamente) incluídas na plataforma Moodle: a) Constructivist On-Line Learning Environment Survey (COLLES); b) Attitudes Towards Thinking and Learning Survey (ATTLS); c) Incidentes Críticos.

\section{Quadro 1 - Critérios de análise das condutas conectada e separada do tutor nas AEF no Moodle}

\begin{tabular}{|c|c|}
\hline Conduta Conectada & Conduta Separada \\
\hline $\begin{array}{c}\text { O tutor participou das discussões durante todo o } \\
\text { período do fórum mantendo o foco no } \\
\text { enunciado? }\end{array}$ & $\begin{array}{c}\text { O tutor apresentou seus argumentos de forma } \\
\text { clara e concisa? }\end{array}$ \\
\hline $\begin{array}{c}\text { O tutor demonstrou compreensão sobre os } \\
\text { argumentos dos outros participantes? }\end{array}$ & O tutor avaliou os argumentos dos outros? \\
\hline $\begin{array}{c}\text { O tutor demonstrou interesse pelos diferentes } \\
\text { argumentos dos estudantes? }\end{array}$ & $\begin{array}{c}\text { O tutor relacionou os conteúdos teóricos da } \\
\text { atividade de estudo com aspectos técnico- } \\
\text { práticos? }\end{array}$ \\
\hline $\begin{array}{c}\text { O tutor considerou importante a experiência } \\
\text { prévia dos estudantes? }\end{array}$ & $\begin{array}{c}\text { O tutor indicou equívocos em comentários de } \\
\text { outros estudantes ou do autor do texto } \\
\text { discutido? }\end{array}$ \\
\hline $\begin{array}{c}\text { O tutor partiu das respostas dos estudantes para } \\
\text { apresentar mais informações sobre o conteúdo } \\
\text { curricular da AEF? }\end{array}$ & $\begin{array}{c}\text { O tutor reafirmou seu posicionamento } \\
\text { discutindo com outros participantes? }\end{array}$ \\
\hline $\begin{array}{c}\text { O tutor procurou produzir colaborativamente com } \\
\text { os estudantes? }\end{array}$ & O tutor questionou comentários dos estudantes? \\
\hline
\end{tabular}

Fonte: Teixeira (2013).

A organização sistemática, a análise e as proposições conclusivas sobre os elementos que circunscrevem a tutoria em relação às condutas conectada e separada foram pautadas na metodologia das três matrizes de pesquisa-ação, idealizadas por Mallmann (2008, 2015): Matriz DialógicoProblematizadora (MDP), Matriz Temático-Organizadora (MTO) e Matriz Temático-Analítica (MTA). A MDP contempla os professores/tutores, estudantes, contexto (AEF no Moodle) e tema (diálogo- 
problematizador e prática colaborativa nas condutas dos tutores), apresentando questionamentos que guiam a pesquisa. A MTO organiza a triangulação dos dados, contendo os tópicos principais das fontes utilizadas. A análise foi realizada a partir de duas categorias: conduta conectada e conduta separada. Ou seja, na análise por categorias, realizamos a triangulação dos dados coletados durante os ciclos da pesquisa. A MTA apresenta as respostas às questões iniciais da MDP. Nesse contexto, as três matrizes (quadros de dezesseis células) tiveram a função basilar de sistematizar metodologicamente as questões orientadoras da pesquisa a fim de delimitar a situação-problema, os principais dados coletados, bem como as respostas às questões orientadoras. Em virtude da sistematização discursiva neste artigo, não é possível integrar os quadros matriciais na íntegra. No entanto, evidenciamos os principais resultados advindos das análises interpretativo-críticas ilustrando com exemplares empíricos.

\section{A Teoria dos Modos de Saber: condutas conectada e separada}

A Teoria dos Modos de Saber foi originalmente desenvolvida no campo da investigação sobre gênero por autores como Belenky et al. (1986) e Clinchy (1996) que procuraram delinear dimensões das diferenças individuais nos modos de desenvolvimento epistemológico pessoal. Belenky et al. (1986) identificaram as epistemologias do saber conectado e separado. Como essa teoria trata de modos de agir em um contexto colaborativo escolar em que o termo saber já é demarcado pelo programa de conteúdos curriculares, optamos por denominar esses dois modos de conduta conectada e conduta separada.

\section{Conduta Conectada}

A conduta conectada foi estudada para ser positivamente correlacionada com a tomada de perspectiva, a preocupação empática e a tendência a ser sensível e reativo à conduta dos outros (KNIGHT; ELFENBEIN, 1998). Knight et al. (2000) explicam que a conduta conectada é uma abordagem em que os sujeitos assumem a perspectiva dos outros em uma tentativa de compreender as suas ideias.

Além disso, Belenky et al. (1986) e Clinchy (1996) propuseram que a conduta conectada surge da experiência de relacionamento: ela requer familiaridade e igualdade entre o eu e o objeto. Referemse também a uma abordagem epistemológica que é subjetiva, em que a pessoa cria tentativas de 
compreender as ideias das outras, assumindo a sua perspectiva.

$\mathrm{Na}$ caracterização da conduta conectada, são bem recorrentes verbos como: compreender, interagir, refletir, perguntar, entender. Dessa forma, associa-se com a interação e a colaboração como princípios fundamentais da EDP freiriana. Isso porque as pessoas que desenvolvem a conduta conectada tendem a aprender a partir da interação, colaboram para a construção de conhecimentos de forma coletiva. Nesse sentido, a interação é entendida como uma ação mútua entre dois ou mais sujeitos que viabiliza a socialização, o desenvolvimento de competências e habilidades, objetivando o ensino-aprendizagem ativo.

Freire (1987, p. 96) destaca que o processo de humanização ocorre a partir do diálogo, ou seja, aprendemos por meio da colaboração, que é compreendida como "característica da ação dialógica, que não pode dar-se a não ser entre os sujeitos, ainda que tenham níveis distintos de função". Além disso, o autor afirma que o diálogo promove um pensar crítico e que, não havendo o diálogo, não existe também a comunicação, logo não existe a verdadeira educação. Nesse sentido, as interfaces epistemológicas entre a TMS e a EDP freiriana são plenamente coerentes. No quadro 2, estabelecemos as relações entre a EDP e a conduta conectada:

\section{Quadro 2 - Relações entre educação freiriana e conduta conectada}

\begin{tabular}{|c|c|}
\hline Educação Freiriana & \begin{tabular}{|c|} 
Conduta Conectada \\
\end{tabular} \\
\hline Ensinar exige disponibilidade para o diálogo. & $\begin{array}{l}\text { Refletir com os outros em torno do objeto de } \\
\text { debate. }\end{array}$ \\
\hline $\begin{array}{l}\text { Ensinar exige risco, aceitação do novo e } \\
\text { rejeição à discriminação. }\end{array}$ & $\begin{array}{l}\text { Colocar-se na posição de outro; } \\
\text { Tentar compreender; } \\
\text { Conviver com diversos tipos de pessoas. }\end{array}$ \\
\hline Ensinar exige querer bem aos educandos. & Compreender por empatia. \\
\hline Ensinar exige saber escutar. & Gostar de ouvir opiniões. \\
\hline 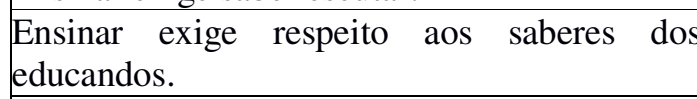 & Entender a experiência prévia das pessoas. \\
\hline Ensinar exige curiosidade. & Saber por quê. \\
\hline
\end{tabular}

Fonte: Teixeira (2013).

Contextualizando esse lastro teórico para as atividades em cursos na modalidade a distância, frisamos a importância de propor questionamentos a fim de que os estudantes despertem curiosidade para aprender. Freire (1996) chama isso de problematização da curiosidade ingênua para construção permanente da curiosidade epistemológica. "O exercício da curiosidade a faz mais criticamente curiosa" (FREIRE, 1996, p. 53), por isso tentar saber o porquê das coisas se torna instigador no 
processo ensino-aprendizagem dialógico. A conduta conectada, desse modo, procura compreender por empatia o motivo de determinada tese, de determinados argumentos, instigando a reflexão em torno do conteúdo que originou a curiosidade (CLINCHY, 1996). Assim, as pessoas estabelecem novos conhecimentos de forma colaborativa.

Desenvolver conduta conectada no âmbito da docência e da tutoria em atividades a distância compreende colaboração entre todos para a construção dos conhecimentos teóricos por meio de atividades de estudo. Ou seja, é fundamental que professores, estudantes e tutores participem ativamente da interação para conceberem conhecimentos colaborativamente, discutindo argumentos, experiências, complementando ideias socialmente (KENSKI, 2003). Essa produção colaborativa é justamente o que se espera nas AEF em ambientes virtuais.

Nesse contexto, durante a análise do Projeto Pedagógico do Curso (PPC), que foi um dos instrumentos da coleta de dados, constatou-se que, na fundamentação teórica dos objetivos, fica explícito que o processo ensino-aprendizagem deve ser desenvolvido conjuntamente e que o diálogo é um fator essencial para a construção do conhecimento. Essa orientação é possível de ser observada na prática dos tutores. No exemplar da Figura 1, é possível verificar uma mensagem em AEF em que o tutor complementa e reflete acerca da resposta do estudante sobre uma atividade de estudo versando sobre os Parâmetros Curriculares Nacionais (PCN) (BRASIL, 1997).

\title{
Figura 1 - Colaboração realizada pelo tutor
}

\begin{abstract}
Re: Comentários sobre os PCN
por $=$ a - quarta, 19 outubro 2011,21:43

esse diálogo, por exemplo, pode ser explorado em inúmeros aspectos. Antes de se propor a pontuação adequada, devemos abrir espaço para discussōes sobre as especificidades do diálogo, suas características, sua relevância, sua finalidade, seu contexto... A partir disso, pode-se discutir sobre a importância dos recursos linguísticos geralmente encontrados no diálogo, e entẫo vai aparecer a pontuaçăo. Nesse momento, parte-se para o estudo da pontuaçẫo a partir do diálogo, compreende?
\end{abstract}

\begin{abstract}
Note que o professor sempre tem de estudar antes de propor em sala de aula umn estudo sobre um gênero textual, pois ele sempre precisa dominar nẫo só as características todas que envolvern um gênero, mas o que pode ser explorado (aspectos gramaticais, por exemplo) a partir dele.

É umn trabalho motivador, nẫo?!

Abraço!
\end{abstract}

Fonte: Teixeira (2013).

O tutor, na Figura 1, pretende colaborar com a proposta inicial da atividade apresentada com o intuito de implementar orientações contidas nos PCN (BRASIL, 1997). Senso assim, notamos que o 
tutor não afirma que a proposição da/o estudante está errada, mas mostra-lhe que existem vários modos de estudar determinados aspectos linguísticos, inclusive destacando que a ideia que propõe é um exemplo. Além disso, sugere uma maneira de sistematização desse trabalho, de forma a demonstrar uma possibilidade de implementar o estudo de um gênero textual a partir das orientações do documento tratado na AEF. Ou seja, não foi identificada uma sobreposição de argumentos, mas uma possibilidade de complementação do que foi apresentado pelo estudante.

Desse modo, no exemplar de mensagem em AEF na Figura 1, o tutor demonstra conduta conectada, já que desenvolve a colaboração ao invés da simples indicação de interpretações inadequadas por parte da estudante. Isto é, o tutor, orientado pelo professor da disciplina, atribuiu sentidos, compreendeu e complementou uma proposição do estudante que poderia apenas ser julgada como inadequada em relação à orientação dos PCN (CLINCHY, 1996). Na figura $2, \quad$ também podemos apreender alguns elementos da conduta conectada do tutor.

\section{Figura 2 - Exemplo de conduta conectada do tutor}

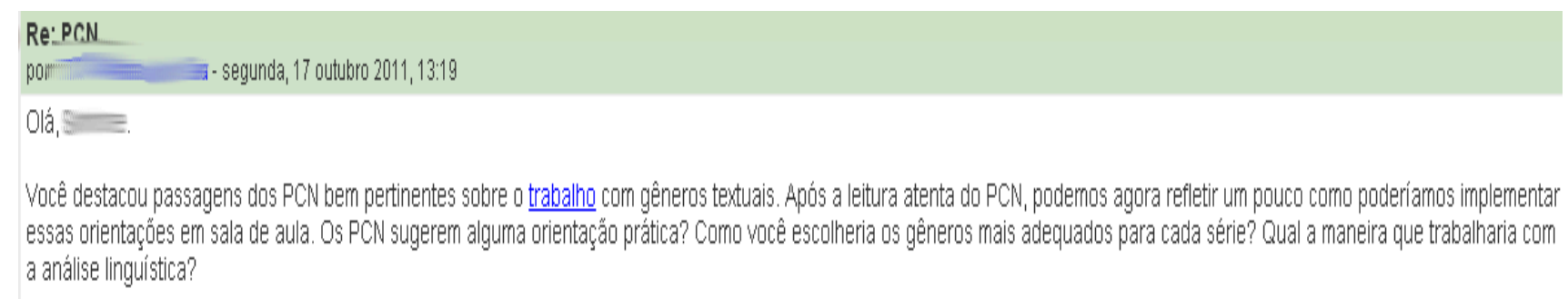

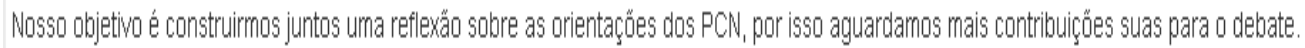

\section{Abraço}

Fonte: Teixeira (2013).

Refletir com os outros é um fator primordial da conduta conectada. Na Figura 2, o tutor procura enfatizar essa ação, a fim de que o estudante perceba a importância de dar sequência ao processo de interação. O tutor também não demonstra ter a intenção de que o estudante tenha apenas uma resposta exata para a questão e sim procura desafiá-lo a pensar sobre o documento que está sendo debatido.

Nesse sentido, o tutor pretende que o conteúdo tratado seja analisado por estudantes que possuam diferentes argumentos e experiências distintas, contestando, questionando certas definições, determinações durante a atividade. Com isso, os estudantes desenvolvem seu senso crítico diante dos conteúdos curriculares. 
Quando responderam ao questionário survey que aplicamos (Figura 3), os tutores concordaram, embora alguns não plenamente, que entre suas atribuições como tutor está a de produzir colaborativamente com os estudantes.

Figura 3 - Produção colaborativa dos tutores

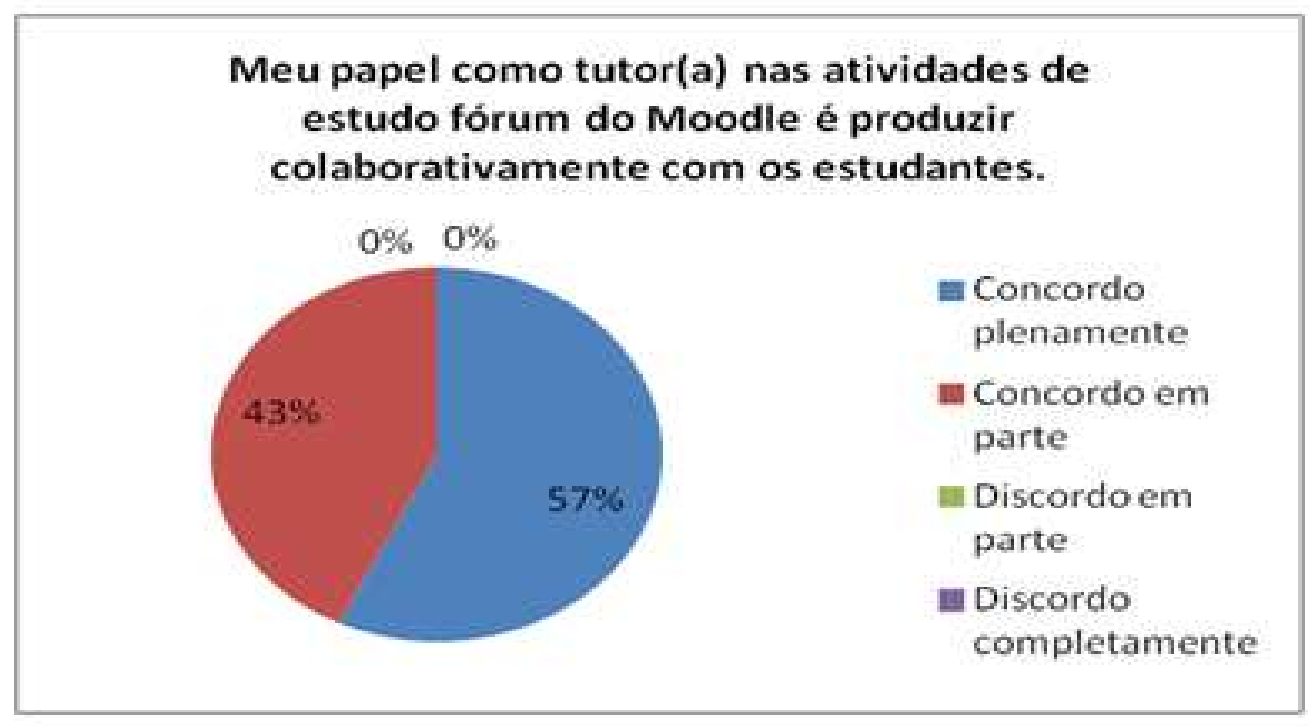

Fonte: Teixeira (2013).

Nesse caso, constatamos que há uma concordância em relação às condutas dos tutores que participaram da pesquisa com as orientações das políticas públicas nacionais e institucionais em relação à concepção educacional que privilegia o diálogo colaborativo. Os tutores, ao colaborarem com os estudantes na $\mathrm{AEF}$, demonstram conduta conectada. E, quando afirmam que o papel dos tutores é produzir colaborativamente na $\mathrm{AEF}$, demonstram que são orientados por pressupostos da conduta conectada.

Os feedbacks apresentados como exemplos de conduta conectada demonstram que comentários como aqueles realizados pelos tutores instigaram a continuidade do processo comunicativo na AEF. Isso porque os estudantes continuaram colaborando após o feedback do tutor. Além disso, as novas respostas dos estudantes demonstraram que eles desenvolveram mais os conhecimentos teóricos a partir do feedback do tutor. Essa conduta, então, busca estabelecer relações para a continuidade no processo de interação e das reflexões sobre o conteúdo estudado, a fim de que a/o estudante elabore conhecimentos novos. 


\section{Conduta Separada}

A conduta separada é uma abordagem na qual os sujeitos questionam as ideias, os argumentos dos outros, preferindo desafio, dúvida. Nela, são mais recorrentes os seguintes verbos: questionar, argumentar, analisar, discordar e avaliar. $\mathrm{Na}$ interface com a teoria dialógica freiriana, encontramos, ainda, o verbo problematizar. Essa conduta se refere a uma abordagem em que os sujeitos desenvolvem pensamento crítico por meio da defesa de seus argumentos pessoais diante do argumento de outras pessoas.

Assim, o seu princípio fundamental é a problematização, que significa tornar os estudantes agentes de sua aprendizagem. Em atividades de estudo a distância, a conduta separada como problematização dos conteúdos curriculares é desenvolvida à medida que tutores e professores fazem os estudantes refletir, pesquisar e repensar posicionamentos e indagações, em vez de apenas apresentar respostas prontas.

As pessoas que desenvolvem conduta separada podem envolver-se em debates, em vez de simples afirmação e contra-afirmação, a fim de julgar argumentações de verdade. As pessoas que assumem a conduta separada, por vezes, têm dificuldade de compreender as respostas dos outros, de forma que o modo típico de discurso é a argumentação. Tais pessoas procuram defender suas opiniões e são um tanto impassíveis às opiniões dos outros. Portanto, parece ficar evidente que na modalidade a distância mediada por tecnologias em rede, especialmente em AEF, é necessário que os envolvidos desenvolvam a conduta separada de modo equilibrado com a conduta conectada. Somente assim, os objetivos das atividades de estudo poderão gerar desenvolvimento intelectual (pessoal e profissional) com base nos conteúdos curriculares específicos das unidades programáticas de cada disciplina.

Se a conduta separada se relaciona com a capacidade de argumentar, questionar, problematizar, a pessoa procura focalizar o argumento, a fim de indicar possíveis equívocos, de modo que, discutindo com outros, possa construir sua própria argumentação. A criticidade torna-se um elemento fundamental, aliada à reflexão sobre a prática e a proposição de desafios (KNIGHT et al., 2000). A conduta separada também procura seguir critérios de avaliação bem definidos, com intuito de manter um julgamento objetivo (CLINCHY, 1996).

As especificidades da conduta separada também se aproximam dos estudos de Freire (1987, 1996), uma vez que se relacionam à problematização dos conteúdos curriculares para adquirir 
conhecimentos teóricos. Em atividades de estudo colaborativas, como o Fórum, é importante que os professores e tutores desenvolvam conduta separada para problematizar as respostas, fazendo os estudantes refletirem sobre suas ideias, ampliando o aprendizado à medida que se analisa criticamente a realidade. Nesse contexto, os estudantes deixam de ser apenas observadores de uma situação e passam a analisá-la de forma crítica a partir da problematização (FREIRE, 1967). Em relação à conduta separada, também é possível estabelecer correlações entre a TMS e a EDP (Quadro 3):

\section{Quadro 3 - Relações entre educação freiriana e conduta separada}

\begin{tabular}{|l|l|}
\hline \multicolumn{1}{|c|}{ Educação Freiriana } & \multicolumn{1}{c|}{ Conduta Separada } \\
\hline Ensinar exige criticidade. & $\begin{array}{l}\text { Focalizar na qualidade do argumento; } \\
\text { Ensinar exige reflexão crítica sobre a } \\
\text { prática. }\end{array}$ \\
\hline Ensinar exige rigorosidade metódica. & $\begin{array}{l}\text { Discordar do autor; } \\
\text { Indicar o ponto fraco; } \\
\text { Usar critérios para avaliar. }\end{array}$ \\
\hline Ensinar exige disponibilidade para o diálogo. & Reforçar discutindo. \\
\hline Ensinar exige problematização. & Submeter a julgamento. \\
\hline
\end{tabular}

Fonte: Teixeira (2013).

Freire (1996) afirma que é no respeito às diferenças e na disponibilidade da realidade que se constitui a segurança. Portanto, nas relações com os outros, que não fizeram exatamente as mesmas escolhas e não tiveram as mesmas experiências, é que se estabelece o debate e a curiosidade que geram a aquisição de conhecimentos teóricos. A submissão ao julgamento, nesse sentido, demonstra a consciência do inacabamento e demonstra a importância da problematização.

Dessa maneira, não se pode afirmar que uma conduta seja superior à outra, pois ambas são aprendidas e são esforços deliberados para adquirir conhecimento (BELENKY et al., 1986; CLINCHY, 1996). Na realidade, as duas condutas coexistem no mesmo indivíduo, apenas com certa tendência ao desenvolvimento mais de uma do que de outra, podendo sua predominância variar ao longo do tempo.

No contexto da pesquisa-ação educacional implementada sobre tutoria, os resultados permitem afirmar sobre a necessidade de as condutas conectada e separada serem desenvolvidas concomitantemente. Isso porque a conduta conectada mantém a relação com outro de forma a compreendê-lo, considerando suas experiências, enquanto que a conduta separada problematiza os elementos que podem ser repensados por meio da reflexão crítica, relacionando teoria e prática. Nesse sentido, do ponto de vista da EDP, é importante que ambas as condutas sejam desenvolvidas, a fim de que haja colaboração e problematização focada nos conteúdos curriculares. 
Assim sendo, observamos que o projeto pedagógico do Curso de Graduação em Letras Português e Literaturas a Distância da UAB/UFSM evidencia a importância de não apenas transmitir conhecimentos e dar respostas prontas aos estudantes. Ao contrário, procura orientar no sentido de que se proponha questionamentos, problematizando-se os conteúdos curriculares, a fim de que os estudantes pensem sobre determinada situação, posicionem-se, pesquisem. Ou seja, os estudantes ajudam a compor o processo ensino-aprendizagem de forma mais ativa, já que terão que construir o conhecimento por meio de argumentos.

$\mathrm{Na}$ Figura 4, apresentamos um exemplo que demonstra a conduta separada de um tutor a partir do feedback proposto por ele. Trata-se da mesma AEF tematizada pelos PCN.

\section{Figura 4 - Exemplo de conduta separada do tutor}

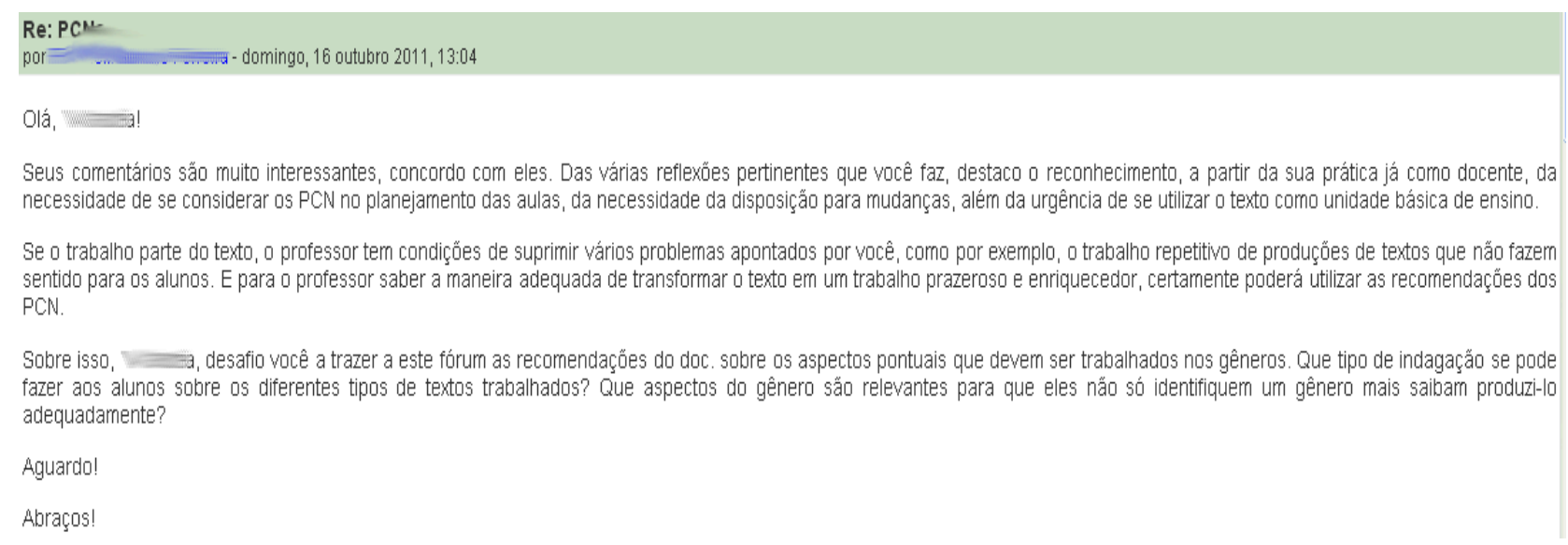

Fonte: Teixeira (2013).

Nesse exemplo de mensagem, o tutor destaca aspectos importantes que foram apresentados pelo estudante: evidencia que fez boas reflexões, inclusive sobre experiências da prática que possui na escola. Ratifica que a leitura realizada por ele é relevante e, a partir dessa compreensão, desafia-o a relacionar as orientações do documento com o estudo dos gêneros textuais por meio de questionamentos. Nesse caso, o tutor problematiza os conhecimentos teóricos desenvolvidos pelo estudante, com a intenção de que este transponha tais conhecimentos para pensar sobre as práticas escolares de língua portuguesa. Assim, o tutor focaliza a qualidade dos argumentos do estudante e realça a reflexão crítica sobre a prática (BELENKY et al., 1986; CLINCHY,1996) .

$\mathrm{Na}$ Figura 5, podemos verificar a problematização realizada pelo tutor em torno da resposta postada por um estudante. 
Figura 5 - Exemplo de problematização realizada pelo tutor

\section{Re: PCN}

por $=$ - domingo, 16 outubro 2011, $15: 50$

Olá, =nenel!

Suas colocaçōes sẵo muito interessantes. Entẵo, pergunto a você: como você acha que o professor pode direcionar o aluno à farniliarizaçăo com umn gênero textual? Que tipo de atividade, de indagaçăa, pode ser feita ao aluno nẫo só para que ele reconheça ưn gênero, mas para que tenha condiçổes de decidir conscientemente sobre que gênero utilizar e como escrever no momento de elaborar um texto?

Além disso, nẵo posso deixar de questionar sobre o que você escreveu no $4^{\circ}$. parágrafo: "mulias vezes eles cansam de estudar as regras do português e precisam de coisas novas, que motivem e desperte o connecimento dos educandos". Você acha que o estudo das regras gramaticais deve ser separado do texto? Quando eles cansarem de estudar as regras, urna possibilidade é estudar um texto? Mas o texto năo é a unidade básica de ensino, de onde devern partir os estudos? Esclareça essa questẩo, ok?

Aguardo.

Abraços!

Fonte: Teixeira (2013).

Inicialmente, o tutor procura destacar que as proposições feitas pelo estudante são relevantes. Entretanto, ainda é necessário que ele reflita, desenvolva mais seus conhecimentos teóricos sobre o tema. Isso é evidenciado a partir dos questionamentos realizados pelo tutor, uma vez que não levam o estudante a responder apenas sim ou não, mas procura fazê-lo pesquisar mais, reler os textos trabalhados, pensar na prática escolar, a fim de que possa de fato concluir quais atividades podem ser realizadas para que os estudantes da educação básica reconheçam e compreendam os gêneros textuais.

Outrossim, o tutor desafia o estudante a retificar um equívoco em sua resposta, sem, entretanto, apenas especificar tal equívoco. No segundo parágrafo, novamente são propostos questionamentos que produziram uma reflexão em torno do assunto. Dessa forma, o estudante pensou sobre sua interpretação inicial da leitura da política pública discutida na AEF, sobre a maneira como expressou isso em sua resposta. Isto é, a partir da problematização do tutor, o estudante conseguiu desenvolver mais sua análise, pensar sobre sua primeira produção e sobre os conteúdos teóricos que estavam sendo trabalhados na atividade de estudo. Nesse caso, o tutor não desconsiderou as proposições feitas pelo estudante, pelo contrário, utilizou-as para fazê-lo pensar sobre o tema discutido. Tal ação vai ao encontro do que Freire (1987) propôs como problematização.

Em relação a seu papel como tutor, os dados coletados por meio de observações e questionário survey demonstram que os tutores têm consciência do seu principal: promover a prática dialógicoproblematizadora (SCHNEIDER; MALLMANN, 2011). Na Figura 6, apresentamos o gráfico relativo a uma das questões aplicadas aos tutores. Nessa questão, $100 \%$ dos tutores concordam plenamente que seu papel na AEF do Moodle é problematizar as respostas dos estudantes de acordo com os objetivos da atividade. 
Figura 6 - Gráfico sobre o papel do tutor nas AEF

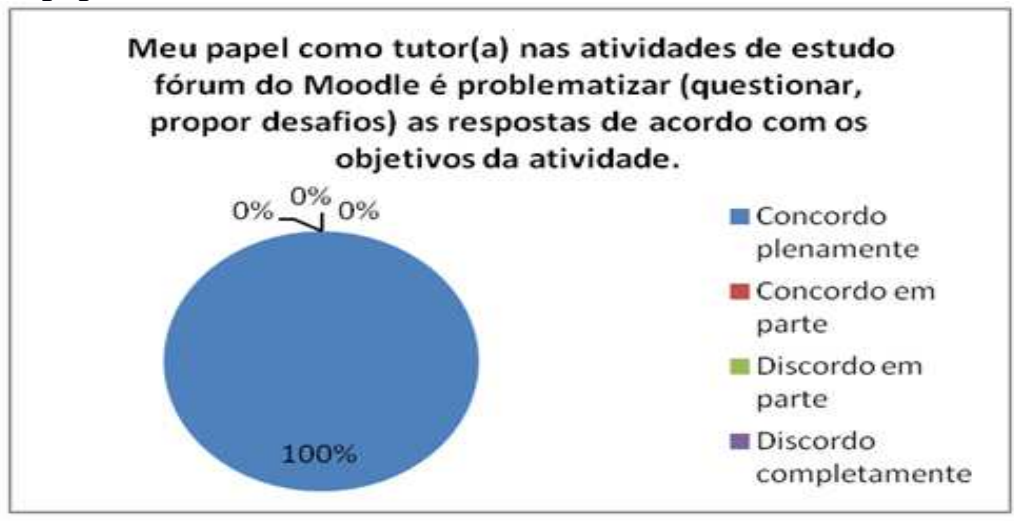

Fonte: Teixeira (2013).

Nesse lastro conceitual, tratamos, a seguir, de forma mais específica, como a TMS na interface com a EDP freiriana apresenta contributos basilares para cursos a distância mediados por tecnologias em rede.

\section{Condutas conectada e separada na Educação a Distância mediada por tecnologias educacionais em rede}

No âmbito da EaD mediada por tecnologias educacionais em rede, a TMS é abordada por Dougiamas e Taylor (2003), que são os idealizadores da plataforma Modular Object-Oriented Dynamic Learning Environment (Moodle) ${ }^{1}$. Essa teoria contribuiu para que os autores desenvolvessem uma estrutura para monitorar a qualidade do discurso em atividades colaborativas nos ambientes virtuais. Eles ainda destacam a conduta conectada e conduta separada, advindas da TMS, como diferentes modos para desenvolver a aprendizagem.

Na pesquisa-ação desenvolvida em curso de formação de professores a distância, ao analisar os impactos das condutas conectada e separada de tutores nas AEF foi possível compreender a necessidade de ambas ocorrerem conjuntamente. As duas são complementares para o desenvolvimento de atividades de estudo colaborativas. Elas contribuem para a realização de práticas educativas que estejam em consonância com as políticas públicas educacionais e com a concepção de educação do curso, e também para o bom andamento de atividades que exigem interação, já que potencializam colaboração e problematização. 
Nesse contexto, Dougiamas e Taylor (2003) defendem uma teoria que trata sobre o conhecimento emancipatório, esclarecendo como a autocrítica e a reflexão em ambientes virtuais podem levar à mudança de perspectiva. Portanto, essa concepção vai ao encontro dos pressupostos da pesquisa-ação e da EDP freiriana. Elliott (1978) explica que, ao acoplar pesquisa à ação, as análises são diagnósticas e obtidas de forma reflexiva e deliberativa. Além disso, essa concepção requer condutas dinâmicas em relação à realidade, proporcionando maior interação social. Assim, permite maior participação e reflexão crítica, bem como uma intencionalidade transformadora das práticas.

É justamente a partir do princípio emancipatório como problematização e colaboração que as interfaces entre a TMS e a concepção educacional dialógico-problematizadora podem ser estabelecidas. Dessa forma, a análise dos princípios necessários à conduta de tutores em AEF tem que levar à compreensão das estratégias didático-metodológicas que podem efetivamente contribuir no desenvolvimento de atividades colaborativas.

Nesse caso, os pressupostos teóricos que sustentaram o desenvolvimento da tecnologia educacional Moodle vão ao encontro da concepção educacional defendida por Freire (1967, 1987, 1996). Logo, fica evidente que, em atividades de estudo a distância em ambientes virtuais, um dos intuitos deve ser justamente incentivar a compreensão do discurso do outro por meio do diálogoproblematizador.

Por isso, o desenvolvimento e o aprimoramento de condutas conectada e separada pautaram-se nos conceitos inerentes à prática reflexiva (COUTINHO et al., 2009): a) reflexão na ação, que compõe o processo de observação durante a prática letiva; b) reflexão sobre a ação, que ocorre num momento posterior à primeira, revendo as ações realizadas; c) reflexão sobre a reflexão na ação, que contribui para o aprimoramento ou alteração nas práticas docentes, visando formular e reorientar novas práticas. Essas práticas reflexivas no exercício da docência e da tutoria em cursos de formação de professores a distância podem gerar condutas que melhoram a compreensão das situações-limites dos estudantes nas atividades de estudo. As condutas conectada e separada de professores e tutores são embasadas em diagnósticos tanto em termos de desafiar os estudantes para novas reflexões quanto em termos de compreensão do percurso que eles realizaram para resolução das atividades propostas.

Para desenvolverem a pesquisa acerca do discurso colaborativo em ambientes virtuais, Dougiamas e Taylor (2003) monitoraram um curso realizado através do Moodle. Utilizaram, principalmente, dois instrumentos de pesquisa integrados à plataforma como ferramentas de atividades, as chamadas Pesquisas de Avaliação, a saber: 1) Attitudes Towards Thinking and Learning Survey 
(ATTLS); 2) Constructivist Online Learning Environment Survey (COLLES); 3) Incidentes Críticos.

A primeira ferramenta pode medir até que ponto uma pessoa é um Connected Knower (CK) ou Separat Knower (SK), que traduzimos por conectado ou separado. A segunda pode ajudar a avaliar as questões-chave sobre a qualidade de um aprendizado em um ambiente virtual - o COLLES é um formulário programado para ajudar os docentes a avaliar, por meio de uma perspectiva socialconstrutivista, a qualidade do ambiente de aprendizagem elaborado por eles. Por fim, terceira é respondida pelos discentes de forma descritiva, a partir de tópicos como: o momento em que esteve mais envolvido e o que esteve menos envolvido; as ações de outros participantes nos fóruns que foram mais esclarecedoras; as ações de outros participantes nos fóruns que foram mais confusas; o evento mais surpreendente.

Assim, pessoas com valores CK maiores tendem a ser mais colaborativas, agradáveis e mais dispostas a construir sobre as ideias dos outros. Já aqueles com escores SK mais altos tendem a assumir uma postura mais crítica, desenvolvendo problematização. Desse modo, implementar pesquisas de avaliação pode gerar diagnósticos para conhecer o perfil das pessoas. Com base nisso, é possível refazer um planejamento de forma a potencializar condutas colaborativas e interativas em cursos mediados por tecnologias educacionais em rede.

O ATTLS é o questionário que foi desenvolvido por Galotti et al. (1999) para diagnosticar até que ponto uma pessoa desenvolve conduta conectada/separada. Esse instrumento de pesquisa está integrado ao Moodle e fornece gráficos e tabelas automaticamente com os resultados. O questionário ATTLS foi aplicado aos estudantes que participaram da AEF na pesquisa-ação desenvolvida. Muitos respondem as perguntas considerando desenvolver a conduta conectada, mas, ao analisar efetivamente os dados fazendo a triangulação com o observável nas atividades de estudo, é possível perceber que há contradições entre o discurso e a prática.

Com base nos estudos realizados sobre as condutas conectada e separada na sua interface com a educação dialógica, avançamos propositivamente. Elaboramos critérios que podem ser usados para avaliar os estudantes em AEF já que a plataforma Moodle oferece um modo de avaliação baseado em escalas. Tais escalas e os critérios propostos são apresentados no tópico seguinte. 


\section{Escalas de avaliação}

Ao longo dos dois anos de pesquisa-ação realizada em curso de formação de professores a distância na UAB/UFSM, registramos diversas avaliações de professores e tutores a respeito da AEF. Muitos a consideram difícil de ser proposta com base em argumentos como: resistência dos estudantes, pois nem sempre acreditam que atividades colaborativas ajudam a adquirir conhecimentos teóricos; resistência dos tutores, pois alguns julgam ser muito trabalhoso realizar o acompanhamento dessa atividade; dificuldades para realizar a avaliação.

Os resultados evidenciam que o desenvolvimento e o aprimoramento de condutas conectada e separada em AEF tornam possíveis, sim, a aquisição de conhecimentos teóricos, especialmente, porque fortalece o desenvolvimento de senso crítico. Além disso, enfatizamos como as condutas conectada e separada podem ser desenvolvidas pelos tutores, a fim de potencializar a problematização e a produção colaborativa em torno dos conteúdos curriculares.

Nesse sentido, com o intuito de apresentar uma nova possibilidade de avaliação para os fóruns, propomos, a seguir, critérios que podem ser utilizados quando se optar por avaliar os estudantes conforme as escalas de avaliação disponíveis no Moodle. Essas escalas podem ser escolhidas como opção de configuração do Fórum (Figura 7).

\section{Figura 7 - Escalas de avaliação}

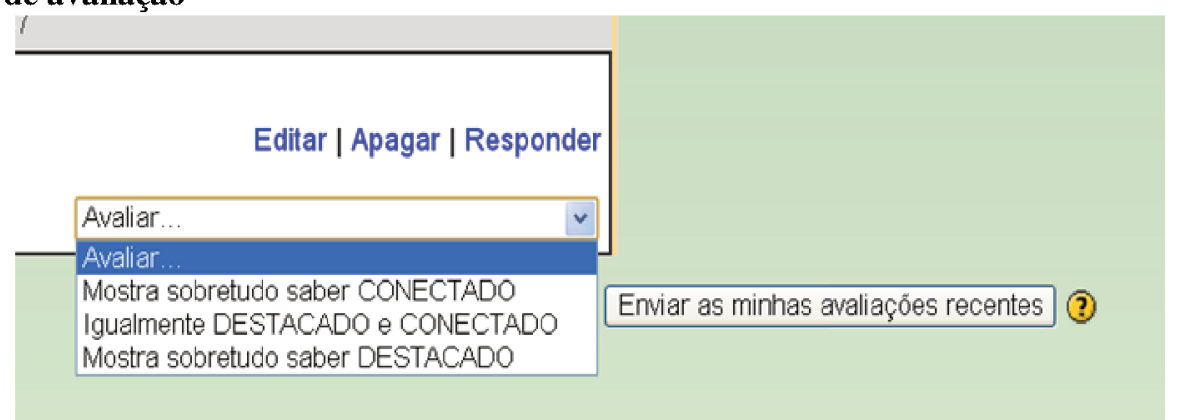

Fonte: Teixeira (2013).

$\mathrm{Na}$ literatura da área não encontramos registros de critérios objetivos que possam auxiliar professores e tutores a avaliar os estudantes de acordo com essas escalas: a) Mostra sobretudo saber Conectado; b) Igualmente Destacado (sinônimo de Separado) e Conectado; c) Mostrado sobretudo saber Destacado. Por isso, a partir de estudos sobre a TMS, das questões que compõem as Pesquisas de Avaliação do Moodle e das relações estabelecidas com a EDP freiriana, elaboramos questões que podem ser usadas para orientar e para avaliar estudantes durante a AEF (Quadro 4). Ao mesmo tempo, 
serve como sugestão propositiva para que professores responsáveis por disciplinas, coordenadores de curso e/ou tutoria avaliem as condutas dos tutores no exercício de suas funções em cursos a distância mediados por tecnologias em rede.

A forma de avaliação por escalas com os critérios bem definidos e compartilhados com os estudantes pode ser pertinente. Isso pode fazer com que, durante sua formação, os estudantes consigam desenvolver condutas dialógico-problematizadoras, já que isso possibilita a educação para a liberdade. Por isso, a escolha pela avaliação das atividades de estudo por meio desses critérios leva o professor a exigir uma prática dos tutores e dos estudantes que ajudem a desenvolver a criticidade, e não apenas reproduzir informações.

Os critérios a seguir (Quadro 4) poderão subsidiar formas de avaliação por rubricas, opção que algumas ferramentas do Moodle já incorporam nas suas versões mais atuais, como por exemplo: ferramenta tarefa a partir da versão 2.2 do Moodle e a ferramenta Laboratório de Avaliação, também chamada em algumas traduções de Workshop, que permite ao professor criar listas de critérios. De acordo com as respostas, podemos avaliar se os estudantes conseguiram ou não desenvolver tais condutas.

Quadro 4 - Critérios para avaliar de acordo com as condutas conectada e separada

\begin{tabular}{|c|c|}
\hline Conduta Conectada & Conduta Separada \\
\hline $\begin{array}{l}\text { O estudante participou das discussões durante } \\
\text { todo o período do fórum mantendo o foco no } \\
\text { enunciado? } \\
\text { ( ) Sim ( ) Não ( ) Em parte }\end{array}$ & $\begin{array}{l}\text { O estudante apresentou seus argumentos } \\
\text { forma clara e concisa? } \\
\text { ( ) Sim ( ) Não ( ) Em parte }\end{array}$ \\
\hline $\begin{array}{l}\text { O estudante demonstrou compreensão sobre os } \\
\text { argumentos dos outros participantes? } \\
\text { ( ) Sim ( ) Não ( ) Em parte }\end{array}$ & $\begin{array}{l}\text { S estudante avaliou os argumentos dos outr } \\
\text { participantes? } \\
\text { ( ) Sim ( ) Não ( ) Em parte }\end{array}$ \\
\hline $\begin{array}{l}\text { O estudante demonstrou interesse pelos } \\
\text { diferentes argumentos? } \\
\text { ( ) Sim ( ) Não ( ) Em parte }\end{array}$ & $\begin{array}{l}\text { O estudante relacionou os conteúdos teóricc } \\
\text { da atividade de estudo com aspectos técnicc } \\
\text { práticos? } \\
\text { ( ) Sim ( ) Não ( ) Em parte }\end{array}$ \\
\hline $\begin{array}{l}\text { O estudante considerou importante } \\
\text { experiência prévia dos colegas? }\end{array}$ & $\begin{array}{l}\text { O estudante indicou equívocos em } \\
\text { comentários de outros estudantes ou do autor } \\
\text { do texto discutido? }\end{array}$ \\
\hline ( ) Sim ( ) Não ( ) Em parte & ( ) Sim ( ) Não ( ) Em parte \\
\hline $\begin{array}{l}\text { O estudante demonstrou curiosidade pelos } \\
\text { assuntos discutidos? } \\
\text { ( ) Sim ( ) Não ( ) Em parte }\end{array}$ & $\begin{array}{l}\text { S estudante reafirmou seu posicioname } \\
\text { discutindo com outros participantes? } \\
\text { ( ) Sim ( ) Não ( ) Em parte }\end{array}$ \\
\hline $\begin{array}{l}\text { O estudante produziu colaborativamente com os } \\
\text { outros participantes? } \\
\text { ( ) Sim ( ) Não ( ) Em parte }\end{array}$ & $\begin{array}{l}\text { S estudante questionou comentários } \\
\text { outros participantes? } \\
\text { ( ) Sim ( ) Não ( ) Em parte }\end{array}$ \\
\hline
\end{tabular}

Fonte: Teixeira (2013). 
Estimamos que as possibilidades de conclusões, conforme as respostas encontradas ao avaliar as $\mathrm{AEF}$ por escalas e critérios, podem ser:

- Maioria das respostas "sim" na coluna da conduta conectada: o estudante demonstrou conduta dialógica, procurando produzir colaborativamente. Ainda é necessário desenvolver mais conduta problematizadora, focando na qualidade do argumento em torno do conteúdo curricular, ou seja, demonstra sobretudo conduta conectada.

- Maioria das respostas "sim" na coluna da conduta separada: o estudante demonstrou conhecimento sobre os conteúdos estudados, conseguindo elaborar bons argumentos e questionamentos para os colegas, desenvolvimento problematização. Ainda é necessário fazer com que interaja mais e compreenda mais as postagens dos colegas, a fim de contribuir com elas, ou seja, demonstra sobretudo conduta separada.

- Maioria das respostas "em parte" ou "não" nas duas colunas: ainda é necessário que os estudantes desenvolvam mais as condutas conectada e separada, pois ainda possuem dificuldades em produzir com os outros e problematizar os conteúdos curriculares. Isso pode ser aos poucos melhorado a partir da conduta dos tutores nas $\mathrm{AEF}$, que podem levar os estudantes a aprimorar essas condutas, isto é, não demonstra condutas conectada e separada.

- Maioria das respostas "sim" nas duas colunas: o estudante conseguiu desenvolver uma conduta dialógico-problematizadora. Nesse caso, o estudante conseguiu desenvolver argumentos que demonstraram concepções, explicaram ideias, além de problematizar as respostas dos outros estudantes, levando à produção colaborativa entre os participantes do grupo, ou seja, demonstra igualmente conduta conectada e separada.

Nesse contexto, podemos observar novamente que é importante que os estudantes consigam desenvolver as duas condutas. Entretanto, devido à maioria dos estudantes estarem habituados à educação por tarefas individuais, que visa mais à repetição, transmissão de conteúdos, muitos podem apresentar dificuldades, como: indisposição para o diálogo e dificuldades em compreender as problematizações. Por isso, é fundamental que os tutores desenvolvam, aprimorem e implementem condutas conectada e separada. Assim, a aposta é que se possa realizar, de fato, educação dialógicoproblematizadora para possibilitar que os estudantes tenham mais autonomia, desenvolvam o senso crítico e construam conhecimentos de forma colaborativa. A partir desses critérios, os professores podem, se necessário para o sistema de avaliação institucional, estabelecer uma pontuação de acordo com as respostas dos estudantes e seus objetivos com a AEF. 


\section{Considerações finais}

Os tutores, no contexto de cursos a distância mediados por tecnologias em rede, especialmente os ambientes virtuais, mantêm contato frequente com os estudantes. Sua função consiste em auxiliá-los a relacionar os conteúdos teóricos das atividades de estudos com os aspectos técnico-práticos dos conteúdos curriculares abordados nas disciplinas. Por isso, é primordial que desenvolvam conduta conectada e separada como diálogo-problematizador para potencializar a constituição do processo ensino-aprendizagem reflexivo e crítico acerca dos conteúdos curriculares.

Nesse sentido, é possível afirmar que condutas conectada e separada dos tutores nas AEF no Moodle são basilares para potencializar a problematização e a produção colaborativa em torno dos conteúdos curriculares. Para tanto, em relação à conduta conectada, é fundamental que o tutor:

- participe das discussões durante todo o período do fórum, mantendo o foco no objetivo central da AEF e no conteúdo curricular abordado;

- demonstre interesse e compreensão sobre os diferentes argumentos apresentados, considerando a experiência prévia dos estudantes;

- parta das respostas dos estudantes para apresentar mais informações sobre o conteúdo curricular da AEF, produzindo colaborativamente.

Em relação à conduta separada, é essencial que o tutor:

- apresente seus argumentos de forma clara, concisa e coerente com o assunto abordado pela AEF e tratado pelos estudantes sobre o conteúdo curricular;

- relacione os conteúdos teóricos da atividade de estudo com aspectos técnico-práticos;

- indique equívocos em comentários de outros estudantes ou do autor do texto discutido;

- reafirme posicionamentos contribuindo com as discussões, a fim de problematizar os argumentos apresentados pelos outros participantes.

Sendo assim, é importante que as condutas conectada e separada ocorram concomitantemente, já que elas visam melhorar a comunicação em atividades de estudo colaborativas, possibilitando a colaboração e a problematização em torno dos conteúdos curriculares. Isso porque a conduta conectada tende a manter a relação com outro de forma a compreendê-lo, entendendo seus motivos, considerando suas experiências, para que, pelo desenvolvimento da conduta separada, seja possível problematizar argumentos que podem ser repensados pelos estudantes por meio de análise crítica dos conhecimentos 
teórico-práticos. Portanto, as duas condutas são imprescindíveis para o desenvolvimento da prática dialógico-problematizadora, potencializando colaboração e problematização, com o intuito de adquirir conhecimentos teórico-científicos.

Os resultados indicam que condutas conectada e separada dos tutores, nas AEF em ambientes virtuais, promovem diálogo-problematizador e produção colaborativa desde que eles desenvolvam fluência nos conteúdos, no modelo pedagógico e nas tecnologias em rede. Diante disso, é possível afirmar que os princípios da TMS na interface com a EDP são basilares para potencializar a problematização conceitual e a produção colaborativa em torno dos conteúdos curriculares na educação a distância.

\section{Nota}

${ }^{1}$ Disponível em: <http://docs.moodle.org/24/en/About_Moodle>.

\section{REFERENCIAS}

BELENKY, Mary Field et al. Women's ways of knowing: the development of self, voice, and mind. New York: Basic Books, 1986.

BRASIL. Ministério da Educação. Secretaria de Educação Fundamental. Parâmetros Curriculares Nacionais: Brasília: MEC/SEF, 1997.

CLINCHY, Blyte M. Connected and separate knowing: toward a marriage of two minds. The Polanyi Society, Joseph, 1996. Disponível em:

$<$ https://www.missouriwestern.edu/orgs/polanyi/kdpChapter.pdf>. Acesso em: 20 jul. 2011.

COUTINHO, Clara P. et al. Investigação-Acção: metodologia preferencial nas práticas educativas. Psicologia, Educação e Cultura, Braga, v. 13, n. 2, dez. 2009.

DAVIDOV, Vasili. What is real learning activity? In: HEDEGAARD, Mariane; LOMPSCHER, Joachim. Learning activity and development. Aarhus: Aarhus University Press, 1999. p. 332.

DOUGIAMAS, Martin; TAYLOR, Peter C. Moodle: using learning communities to create an open source course management system. Dougiamas, 2003. Disponível em:

<http://dougiamas.com/writing/edmedia2003/>. Acesso em: 1 jun. 2011.

ELLIOTT, John. What is Action-Research in Schools? Journal of Curriculum Studies, v. 10, n. 4, p. 335-337, 1978.

FREIRE, Paulo. Educação como prática da liberdade. Rio de Janeiro: Paz e Terra, 1967. 
FREIRE, Paulo. Pedagogia da Autonomia: saberes necessários à prática educativa. 31. ed.

São Paulo: Paz e Terra, 1996.

FREIRE, Paulo. Pedagogia do Oprimido. 17. ed. Rio de Janeiro: Paz e Terra, 1987.

GALOTTI, Kathleen M. et al. A new way of assessing ways of knowing: the Attitudes Towards Thinking and Learning Survey (ATTLS). Sex Roles, v. 40, n. 9, p. 745-766, 1999.

KENSKI, Vani Moreira. Tecnologias e ensino presencial e a distância. Campinas, SP: Papirus, 2003.

KNIGHT, Kim H. et al. Relationship of connected and separate knowing to parental style and birth order. Sex Roles, v. 43, n. 3, p. 229-240, 2000.

KNIGHT, Kim H.; ELFENBEIN, Morton H. Relationship of connected and separate knowing interpersonal orientation, argumentativeness, and fear of negative evaluation. In: ANNUAL ADULT DEVELOPMENT SYMPOSIUM, 13., 1998, Montpelier. Proceedings Montpelier, 1998.

LEWIN, Kurt. Action research and minority problems. In: LEWIN, G. W. Resolving social conflict. London: Harper \& Row, 1946.

MALLMANN, Elena Maria. Mediação pedagógica em educação a distância: cartografia da performance docente no processo de elaboração de materiais didáticos. 2008. 304f. Tese (Doutorado em Educação) - Universidade Federal de Santa Catarina, Florianópolis, 2008.

MALLMANN, Elena Maria. Pesquisa-ação educacional: preocupação temática, análise e interpretação crítico-reflexiva. Cadernos de Pesquisa, São Paulo, v. 45, p. 7698, 2015.

SCHNEIDER, Daniele da Rocha; MALLMANN, Elena Maria. Tutoria em educação a distância: indicadores para políticas públicas. In: CONGRESSO INTERNACIONAL ABED DE EDUCAÇÃO A DISTÂNCIA, 17, 2011, Manaus. Anais ABED, 2011.

TEIXEIRA, Tatiana Gloor. Condutas conectada e separada dos tutores da UAB/UFSM nas atividades de estudo fórum no Moodle. Santa Maria: Dissertação de Mestrado em Educação. PPGE/UFSM, 2013, $147 \mathrm{p}$. 


\section{Theory of Modes of Knowing and Dialogic Education Teacher Training Courses Distance: conduct of study tutors in Forum activities}

\begin{abstract}
The aim is to comprehend how the tutors' separate and connected conducts on the forum study activities at the Moodle enhance problem-posing dialogue and collaborative production regarding the curricular contents. We problematize the ducts of the tutors in the Forum study activities in the virtual environment of a training course for teachers away from UAB/UFSM. The analysis of the tutors' conducts on the forum study activities at the Moodle was conducted based on data obtained from survey type questionnaires, participant observation and course documents, according to the action research theoretical-methodological presuppositions. The analysis was categorized by separate conducts connected and grounded in the theory of modes of knowing and dialogical education. The research results indicate that the tutors' separate and connected conducts, on the forum study activities at the Moodle, promote problem-posing dialogue and collaborative production as long as they develop fluency in the contents, pedagogical model and the network technologies. The findings point out that the principles of the theory of modes of knowing at the interface with the dialogic education are fundamental to enhance the conceptual questioning and collaborative production around the curricular content in distance education.
\end{abstract}

Keywords: Distance Education. Tutoring. Forum.

Elena Maria Mallmann

E-mail: elena.ufsm@gmail.com
Teoría de las Formas de saber y educación dialógica en los cursos de Formación del Profesorado en la educación a Distancia: conducta de los tutores de estudios en las actividades del Foro

\section{Resumen}

El objetivo es entender cómo las conductas de los tutores en actividades a distancia potencializan el diálogo y los contenidos curriculares de producción alrededor de la resolución de problemas en colaboración. Se problematizó las conductas de los tutores en las actividades de estudio del Foro en el entorno virtual de un curso de formación para profesores a distancia de la UAB/UFSM. De acuerdo con los supuestos teóricos y metodológicos de la investigación-acción, los procedimientos de aproximación incluyen cuestionarios tipo survey, observación participante y análisis de la documentación del curso. El análisis se clasificó por conductas conectadas y separadas a partir de la teoría de los modos de conocimiento y la educación dialógica. Los resultados indican que conductas conectada y separada de los tutores en las actividades de estudio del Foro en ambientes virtuales, promueven el diálogo, la resolución de problemas y la colaboración de producción siempre que se desarrolle la fluidez en el contenido, el modelo pedagógico y las tecnologías de red. Los resultados señalan que los principios de la teoría de los modos de conocimiento en la interface con la educación dialógica son fundamentales para la potencialización conceptual y la producción colaborativa en torno de los contenidos curriculares en la educación a distancia.

Palabras claves: Educación Dialógica. Educación a Distancia. Tutoria. Foro.

Enviado em: 20/4/2014

Aprovado em: 4/8/2015 